\title{
Effect of caffeine on pneumogram and apnoea of infancy
}

\author{
M ANWAR, H MONDESTIN, N MOJICA, R NOVO, M GRAFF, M HIATT, AND T HEGYI
}

Department of Pediatrics, UMDNJ-Rutgers Medical School and Monmouth Medical Center, New Brunswick, New Jersey, United States of America

SUMMARY We studied the efficacy of caffeine in improving pneumogram abnormalities and relieving clinically important apnoea of infancy in 23 infants. After obtaining a 12 hour pneumogram we administered caffeine citrate in a loading dose of $20 \mathrm{mg} / \mathrm{kg}$ followed by $5 \mathrm{mg} / \mathrm{kg}$ once daily. This dose achieved a trough caffeine blood concentration of 9.6 (SD 2.0) $\mu \mathrm{g} / \mathrm{ml}$. A repeat pneumogram performed seven to 10 days after the first pneumogram showed a significant reduction in the number of short and prolonged attacks of apnoea as well as in the per cent periodic breathing and apnoea density. Episodes of prolonged apnoea disappeared in all infants after administration of caffeine and in 11 infants all pneumogram abnormalities resolved. This improvement in the results of pneumograms was associated with resolution of clinically important apnoea requiring intervention. Caffeine was administered for 3.4 (SD 1.3) months and was well tolerated by all except two infants. We conclude that treatment with caffeine is helpful in preventing attacks of apnoea that require intervention, and improvement in the results of pneumograms after administration of caffeine predicts this favourable response.

Apnoea has been recognised as a major problem in many preterm and some full term infants before discharge from the nursery. ${ }^{12}$ Evaluation in these infants usually fails to identify any underlying cause for the attacks of apnoea. Prolonged attacks of apnoea, especially in premature infants, are apparently not predictive of sudden infant death syndrome ${ }^{1}{ }^{3}$ but are often perceived by parents and physicians as a life threatening event with a risk of recurrence. Home monitoring has therefore been suggested in the management of these infants with unexplained apnoeic or cyanotic episodes. ${ }^{45}$ In addition, treatment with theophylline has also been found to be an effective adjunct in the care of these infants. ${ }^{6}$ Apnoea of prematurity can be treated with caffeine, ${ }^{8}$ which has a wider safety margin than theophylline. ${ }^{9}$ While the two abnormalities in the control of ventilation - that is, apnoea of prematurity and persistent infantile apnoea-may result from different mechanisms, we hypothesised that caffeine may be better suited for home use. As no systematic evaluation of caffeine has been performed in home circumstances we decided to evaluate the effect of home administration of caffeine on breathing patterns as measured by 12 hour pneumogram and on the incidence of clinically important apnoea.

\section{Subjects and methods}

We studied 19 preterm infants ready for discharge from the newborn nursery who were suffering from clinically important apnoea. We defined clinically important apnoea as a respiratory pause of at least 20 seconds in duration or less if accompanied by cyanosis or bradycardia. ${ }^{4}$ We also studied four full term infants with clinically important apnoea, two of whom developed apnoea while they were still in the newborn nursery and two at home. Initial evaluation focused on the exclusion of the following medical conditions known to cause apnoea: infection, hypoglycaemia, hypocalcaemia, electrolyte imbalance, seizure disorder, gastro-oesophageal reflux, intracranial abnormalities, and congenital and chromosomal anomalies when appropriate. If an underlying cause for apnoea was identified appropriate treatment was begun. Infants with unexplained apnoea, requiring manual stimulation or bag and mask ventilation to terminate an episode of apnoea, were considered appropriate candidates 
for home monitoring and treatment with caffeine and formed the subjects for this study.

Caffeine was administered orally as caffeine citrate in a loading dose of $20 \mathrm{mg} / \mathrm{kg}$ followed by a maintenance dose of $5 \mathrm{mg} / \mathrm{kg}$ once daily. Maintenance caffeine was started 24 hours after the loading dose. We measured caffeine trough concentration in the blood (half to one hour before the dose) after five to seven days of treatment. Caffeine dosage was adjusted to maintain a blood concentration of $6-15 \mu \mathrm{g} / \mathrm{ml}$.

We obtained 12 hour pneumogram recordings before and seven to 10 days after administration of caffeine. Subsequent pneumograms were obtained as clinically indicated. Pneumograms are two channel, slow speed recordings; one channel for electrocardiogram and one for respiratory pattern, as detected by thoracic impedance. The pre-caffeine pneumogram was performed in the hospital and the post-caffeine recording at home.

We used Medical Graphics Corporation (MGC) System 5000 to analyse the results of our pneumograms. The MGC Computer Assisted Pneumogram provides a scoring system, on a breath by breath basis, as a summary report and graphic display of apnoea, bradycardia, and periodic breathing. The computer system is capable of analysing the pneumogram in greater detail than is possible manually, and observer bias in analysis is eliminated. We visually checked the electrocardiogram and respiratory pattern tracing for artefacts and excluded all portions of the tracings with artefacts from analysis. As no control data for pneumogram analysis in premature infants using MGC System 5000 is available we also studied 15 infants with a birth weight of 1620 (SD 320) $\mathrm{g}$ and gestational age of 32.2 (SD 1.5) weeks at a postnatal age of 5.7 (SD 2.3) weeks, who were ready for discharge from the newborn nursery and had not had any attacks of apnoea.

We defined periodic breathing as three or more respiratory pauses of three seconds or longer interrupted by respiration for less than 20 seconds. The per cent periodic breathing was calculated by divi- ding the number of minutes of periodic breathing by the number of minutes of sleep time. We defined apnoea density as time spent in apnoea (duration of over six seconds) for each 100 minutes of sleep time.

All study infants were discharged home on cardiorespiratory monitors, which detect heart rate by the electrocardiographic signal and respiration by the impedance signal. The monitor has an alarm for attacks of apnoea as well as of bradycardia and tachycardia. In addition, the monitor has an audible beep and a flashing light to indicate the instantaneous heart rate and another light to indicate loose leads. We set the respiratory alarm to sound at 15 seconds of apnoea, the bradycardia alarm at heart rate less than two thirds of the baseline, and the tachycardia alarm at heart rate over 180 beats/ min. All parents were given instruction in the use of the monitor and cardiopulmonary resuscitation. Parents were also instructed to maintain a diary of all alarms and interventions undertaken by them. We interviewed all parents in the neonatal follow up clinic to assess any complications related to the use of caffeine as well as the details of any attacks of apnoea or intervention reported by them.

Results are expressed as mean (SD). We used the Wilcoxon signed rank test to analyse the difference in the breathing pattern before and after administration of caffeine and the Wilcoxon rank sum test to compare control infants and infants with attacks of apnoea, which are distribution free methods (as the variables analysed are often not normally distributed). Categorical data were evaluated by $\chi^{2}$ test. Results were considered significant if $\mathrm{p}<0.05$.

\section{Results}

Clinical characteristics of our study infants are shown in Table 1. Response to caffeine was similar in the two groups so the pneumogram results have been combined in Tables 2 and 3. Caffeine steady state blood concentration before the second pneumogram was $9.6(2.0) \mu \mathrm{g} / \mathrm{ml}$.

Total number of apnoeic episodes recorded on the 12 hour pneumogram performed before and after

Table 1 Clinical characteristics of the study infants. Values are mean (SD)

\begin{tabular}{|c|c|c|c|}
\hline & \multirow[t]{2}{*}{ Full term infants } & \multicolumn{2}{|c|}{ Preterm infants } \\
\hline & & Controls & With attacks of apnoea \\
\hline No & 4 & 15 & 19 \\
\hline Birth weight (g) & $2800(430)$ & $1620(320)$ & $1600(600)$ \\
\hline Gestational age (weeks) & & $32.2(1.5)$ & $32 \cdot 0(2 \cdot 6)$ \\
\hline Weight at first phonocardiogram (kg) & $4 \cdot 0(2 \cdot 4)$ & $2 \cdot 1(1 \cdot 2)$ & $2 \cdot 2(1 \cdot 1)$ \\
\hline $\begin{array}{l}\text { Postnatal age at first } \\
\text { phonocardiogram (weeks) }\end{array}$ & $2 \cdot 0(1 \cdot 5)$ & $5.7(2.3)$ & $5.0(3,2)$ \\
\hline
\end{tabular}


Table 2 No of apnoeic episodes in control group and infants with apnoea

\begin{tabular}{|c|c|c|c|}
\hline & \multirow[t]{2}{*}{ Control group $(n=15)$} & \multicolumn{2}{|c|}{ Infants with apnoea $(n=23)$} \\
\hline & & Before caffeine & After caffeine \\
\hline \multicolumn{4}{|c|}{ Duration of attack of apnoea (secs): } \\
\hline $5-6$ & $6(5)$ & $67(54)$ & $22(31)^{*}$ \\
\hline $7-10$ & $1(2)$ & $34(35)$ & $9(17)^{*}$ \\
\hline $11-15$ & 0 & 7 (19) & $2(7)$ \\
\hline$>15$ & 0 & $8(2)$ & $0^{*}$ \\
\hline$\%$ Periodic breathing & $0.3(0.4)$ & $4 \cdot 4(4 \cdot 2)$ & $1.2(2.0)^{*}$ \\
\hline Apnoea density & $0 \cdot 1(0 \cdot 1)$ & $1.0(0.9)$ & $0.3(0.5)^{*}$ \\
\hline
\end{tabular}

*Significant difference $(p<0.05)$ in infants with apnoea in relation to treatment with caffeine.

administration of caffeine is shown in Table 2. Also contrasted in this Table are the pneumogram findings of normal premature infants before discharge from the newborn nursery. There was a significant difference between the control group and infants with attacks of apnoea before treatment with caffeine in all categories studied except for attacks of apnoea lasting 11-15 seconds. In infants with attacks of apnoea administration of caffeine was associated with a significant reduction in the total number of attacks in all categories analysed except for attacks lasting 11-15 seconds. Prolonged attacks (over 15 seconds in duration) or attacks associated with bradycardia were not seen after administration of caffeine. In addition, per cent periodic breathing and apnoea density were also significantly reduced. In comparison with the control group, infants with attacks of apnoea after administration of caffeine continued to have a significantly higher number of attacks in the 5-6 second category of apnoea. In all other categories of apnoea, per cent periodic breathing, and apnoea density, however, the control group was not significantly different from the group with attacks of apnoea after treatment with caffeine.

The number of infants with one or more attacks of apnoea before and after administration of caffeine as recorded on the pneumograms is shown in Table 3. Eleven infants became free of attacks of apnoea after administration of caffeine. Twelve infants continued to have short attacks, none of whom, however, had prolonged attacks (over 15 seconds in duration) or attacks associated with bradycardia. Also shown in Table 3 is the number of infants with periodic breathing in excess of $3.5 \%$ and apnoea density in excess of $1.5 \%$ in relation to treatment with caffeine. While these cut off values for excessive periodic breathing and apnoea density are not totally discriminative, infants with apnoea of infancy generally have values above and normal infants below these cut off values. ${ }^{10} 11$ The reduction in the number of infants with attacks of apnoea in all categories and excessive periodic breathing after adminsitration of caffeine is significant except for attacks lasting 11-15 seconds. The reduction in the number of infants with apnoea density over $1.5 \%$ in relation to administration of caffeine is not significant.

Home evaluation of our study infants showed that false alarms on the monitors were common. These alarms were related to loose leads and short episodes of bradycardia lasting less than 3-5 seconds (perhaps related to transient vagal stimulation). None of our study infants, however, had prolonged attacks of apnoea (over 15 seconds) or attacks associated with colour change or bradycardia requiring intervention (manual stimulation or mouth to mouth ventilation) while on caffeine. Two infants became irritable, restless, and jittery after starting treatment with caffeine. These symptoms resolved after stopping treatment with caffeine, and subsequently theophylline was well tolerated by them. Theophylline was administered to these infants one to two weeks after the second pneumogram and so did not affect the pneumogram analysis. The remaining 21 infants received caffeine for $3.4(1.3)$ months. Seventeen infants had no obvious harmful effects related to caffeine. Four infants were judged by their parents to be somewhat more irritable and restless while on caffeine. Their daily activity, sleep,

Table 3 No of infants with breathing pattern abnormalities before and after treatment with caffeine

\begin{tabular}{lcl}
\hline $\begin{array}{l}\text { Breathing } \\
\text { pattern }\end{array}$ & $\begin{array}{l}\text { Before } \\
\text { caffeine }\end{array}$ & $\begin{array}{l}\text { After } \\
\text { caffeine }\end{array}$ \\
\hline $\begin{array}{l}\text { No apnoea } \\
\text { Duration of attack }\end{array}$ & 0 & $11^{*}$ \\
$\quad$ of apnoea (secs): & 21 & \\
$5-6$ & 21 & $11^{*}$ \\
$7-10$ & 7 & $12^{*}$ \\
$11-15$ & 7 & 2 \\
$>15$ & 14 & $0^{*}$ \\
$\%$ Periodic breathing & 8 & $2^{*}$ \\
$>3.5$ & & 3 \\
$\%$ Apnoea density & & \\
$>1.5$ & & \\
${ }^{*}$ p $<0.05$. & &
\end{tabular}


and feeding patterns, however, were not altered. Caffeine blood concentrations did not correlate with symptoms and none of the infants had a blood concentration over $16 \mu \mathrm{g} / \mathrm{ml}$.

\section{Discussion}

Most parents display anxiety at the prospect of caring for their infants who suffer from attacks of apnoea at home. Home monitoring is currently an accepted way of managing infants with attacks of apnoea. The ability of anxious parents to deal with an attack of apnoea detected by the monitor is, however, variable. Infants have been known to die of sudden infant death syndrome at home while being monitored. ${ }^{12}$ Death at home in these monitored infants may be due either to the fact that sudden infant death syndrome is not preventable or to the inability of the parents to provide adequate resuscitation. Implicit in the home monitoring of infants with attacks of apnoea is the idea that parents can learn the skills of resuscitation and execute them when needed. To date this assumption is untested and unproven. It is important, therefore, to prevent prolonged attacks of apnoea at home that may require intervention.

Respirogenic properties of the methylxanthines, particularly caffeine, have been known for a long time. The exact site and mechanism of action, however, have not yet been clearly defined. Methylxanthines augment central inspiratory drive and increase chemoreceptor sensitivity to carbon dioxide. ${ }^{9}$ Others factors that may facilitate this anti-apnoeic effect of methylxanthines include improved skeletal muscle contraction, ${ }^{13}$ potentiation of catecholamine response ${ }^{14}$ improved metabolic homeostasis, ${ }^{15}$ and improved oxygenation secondary to increased cardiac output, increased ventilation, and decreased hypoxic episodes. ${ }^{16}$ Our results indicate that caffeine can be safely administered to most of these infants with attacks of apnoea. None of our infants developed clinically important apnoea requiring intervention while on caffeine. Thus our results are in agreement with Murat $e t$ al, who have shown caffeine to be efficacious in recurrent idiopathic apnoea of prematurity in the immediate neonatal period. ${ }^{8}$ The long term harmful effects of caffeine, if any, are, however, unknown. It is prudent, therefore, not to use caffeine unnecessarily.

Pneumograms have been extensively used to evaluate infants at risk for sudden infant death syndrome. Recent data indicate that pneumogram findings are not very helpful in predicting the risk for sudden infant death syndrome. ${ }^{3}$ Pneumogram findings may be quite helpful, however, in predicting the risk for prolonged sleep apnoea, Stein- schneider has shown that infants with prolonged sleep apnoea have, during a single nap, more frequent and longer apnoeic pauses and more periodic attacks compared with normal infants. ${ }^{17}$ Hunt $e t$ al have shown that home pneumograms can differentiate infants with prolonged attacks of apnoea from normal infants with $80 \%$ accuracy. ${ }^{11}$ Our results indicate that improvement in pneumogram abnormalities with administration of caffeine is associated with resolution of prolonged attacks requiring intervention. Thus pneumogram abnormalities in conjunction with response to caffeine can be used to identify infants who are likely to benefit from administration of caffeine.

All of our study infants suffered from clinically important apnoea requiring intervention. Consequently, we were unable to control the environment in which our pneumograms were performed as this would have necessitated an additional seven to 10 days of admission to hospital. Our first pneumogram before administration of caffeine was performed in the hospital, while the second pneumogram after caffeine was performed at home. The effect of environmental changes on pneumogram findings is unknown. Our two measures of short attacks of apnoea, the per cent periodic breathing and apnoea density, should be similar as they are controlled by sleep time. Prolonged attacks of apnoea, on the other hand, may occur more often at home because of the quieter home environment. Our results are, however, contrary to this expectation and may be attributed to the administration of caffeine. Our results can also be criticised because we did not control for the maturational effect of the time interval of seven to 10 days between our first and second pneumogram. Sequential pneumogram changes have been studied by Richards $e t$ al and Hunt et al. ${ }^{211}$ These authors, however, studied only healthy full term infants at intervals of six weeks to three months, which makes comparison with our study difficult. Kelly et al have shown that repeat pneumograms after 5.7 (2.7) days in 11 infants, before treatment with a methylxanthine, did not result in resolution of excessive periodic breathing. ${ }^{6}$ In addition, Hunt et al have shown a significant difference in pneumogram abnormalities between infants with attacks of apnoea studied at $7.7(7 \cdot 1)$ weeks compared with control infants at 1 and 3 months of age. ${ }^{11}$ From these studies we conclude that infants with attacks of apnoea have persistent breathing pattern abnormalities that are not likely to resolve spontaneously within seven to 10 days. This conclusion is supported by the findings in two of our study infants who developed side effects from treatment with caffeine that necessitated stopping this drug after one week in one infant and two weeks 
in the other. Both of these infants had a recurrence of apnoea requiring intervention.

In conclusion, our data show that caffeine improves pneumogram abnormalities in infants suffering from attacks of apnoea. In addition, this improvement in pneumogram findings is associated with resolution of clinically important apnoea requiring intervention.

The authors gratefully acknowledge the technical help provided by Sheila Bereheiko and Kathy Smith.

\section{References}

${ }^{1}$ Southall DP, Richards JM, Rhodes KJ, et al. Prolonged apnea and cardiac arrhythmias in infants discharged from neonatal intensive care units: failure to predict an increased risk for sudden infant death syndrome. Pediatrics 1982;70:844-51.

2 Richards JM, Alexander JR, Shinebourne EA, et al. Sequential 22-hour profiles of breathing patterns and heart rate in 110 full term infants during their first 6 months of life. Pediatrics 1984;74:763-77.

${ }^{3}$ Southall DP, Richards JM, de Swiet M, et al. Identification of infants destined to die unexpectedly during infancy: evaluation of predictive importance of prolonged apnoea and disorders of cardiac rhythm and conduction. Br Med J 1983;286:1092-6.

4 Task Force on Prolonged Infantile Apnea of The American Academy of Pediatrics. Prolonged infantile apnea: 1985. Pediatrics 1985;76:129-31.

${ }^{5}$ Foundation for the Study of Infant Death and The British Respiratory Group. Apnoea monitors and sudden infant death. Arch Dis Child 1985;60:76-80.

${ }^{6}$ Kelly DH, Shannon DC. Treatment of apnea and excessive periodic breathing in the full-term infant. Pediatrics 1981;68: 183-6.
${ }^{7}$ Hunt CE, Brouillette RT, Hanson D. Theophylline improves pneumogram abnormalities in infants at risk for sudden infant death syndrome. J Pediatr 1983;103:969-74.

${ }^{8}$ Murat I, Moriette G, Bliss MC, et al. The efficacy of caffeine in the treatment of recurrent idiopathic apnea in premature infants. J Pediatr 1981;99:984-9.

9 Aranda JV, Ttrmen T. Methylxanthines in apnea of prematurity. Clin Perinatol 1979;6:87-108.

10 Kelly DH, Stellwagen LM, Kaitz E, Shannon DC. Apnea and periodic breathing in normal full term infants during the first twelve months. Pediatric Pulmonology 1985;1:215-9.

11 Hunt CE, Brouillette RT, Hanson D, et al. Home pneumograms in normal infants. $J$ Pediatr 1985;106:551-5.

12 Kelly DH. Incidence of severe apnea and death in infants identified at high risk for sudden infant death syndrome. In: Tildon JT, Roeder LM, Steinschneider A, eds. Sudden infant death syndrome. New York: Academic Press, 1983:607-13.

${ }^{13}$ Aubier M, Murciano D, Viiries N, et al. Diaphragmatic contractility enhanced by aminophylline: role of extracellular calcium. J Appl Physiol 1983;54:460-4.

${ }^{14}$ Rall TW, West TC. The potentiation of cardiac inotropic response to norepinephrine by theophylline. J Pharmacol Exp Ther 1963;139:269-74.

15 Aranda JV, Dupont C. Metabolic effects of methylxanthines in premature infants. J Pediatr 1976;89:833-4.

16 Rall TW. Central nervous system stimulants. 2. The xanthines. In: Goodman LS, Gilman A, eds. The pharmacological basis of therapeutics. 7th Ed. London: MacMillan, 1985:589-603.

17 Steinschneider A. Prolonged sleep apnoea and respiratory instability: a discriminative study. Pediatrics 1977;59:962-70.

Correspondence to Dr M Anwar, St Peter's Medical Center, New Brunswick, NJ 08903, United States of America.

Received 21 May 1986 